\title{
Exchange Rate Fluctuation and Tourism Sector Output in Nigeria
}

\author{
${ }^{1}$ Ogbeba Ehigocho Peace, ${ }^{2}$ Oji-Okoro Izuchukwu, ${ }^{3}$ Abba Abubakar Shehu \\ ${ }^{1,2}$ Department Economics, Faculty of Social Sciences, Federal University Lafia, P.M.B 146 Lafia, Nasarawa \\ State, Nigeria \\ ${ }^{3}$ National Institute for Hospitality and Tourism, Northwest Zonal Campus, Bagauda Kano, Nigeria
}

\begin{abstract}
It has been a major source of contention among economics scholars, that tourism is a major driver of socioeconomic development in the world and serves as a major source of revenue across countries. Hence, this paper examines the effects of exchange rate fluctuation on tourism sector output in Nigeria for the period of 1995 to 2015, using the Vector Error Correction Model (VECM), granger causality test and co-integration approach to ascertain this relationship. Results revealed that exchange rate fluctuation indeed has a significantly negative effect on tourism sector output in Nigeria, and that an increased fluctuation reduces the contribution of the tourism sector to GDP. The granger Causality test result showed that there is a unidirectional causality and long run relationship between contribution of tourism sector to GDP and the contribution of the Tourism sector to employment, real effective exchange rate, and the international number of tourist arrival. Among various recommendations in the study is for the government of Nigeria to review existing economic policies that affect the exchange rate fluctuation, as these some of this policies may be responsible for the consistent increase in exchange rate fluctuation, as these could substantially reduce the number of tourist arrival and tourism sector output.
\end{abstract}

Keywords: Exchange Rate Fluctuation, Tourism Sector, Granger Causality, Vector Error Correction, Gross Domestic Product.

\section{Introduction}

The Tourism sector serves as a major driver of socio-economic development in most developed countries around the world; this sector has been a major source of revenue across countries and is an alternative strategy for sustainability and diversification of an economy. The development of tourism attractions becomes very crucial in Nigeria if we must diversify into this sector. Tourism has become one of the most important sector in most developing countries having already overtaken cash crop agriculture and other primary industries as major source of national income, export earnings and generation of employment (Orgu 2010). Tourism industry around the world have experience a great revolution for the past 3 decades, both public and private tour operators have taken the opportunities available to venture into business activities that can attract tourists to their countries. In an attempt to harness from the opportunities inherent in tourism industry, major economies around the world have designed their regions, cities and states in a manner that both tourist and investors in the tourist sector will be attracted.(Gil \& Ritchie, 2008). The number of tourist and tourist expenditure has considerable effect on income, government income, and employment, balance of payment, environments and culture of destination areas. Increase in tourism demand will lead to an increase in employment, income, output and increase in inflation, an increase in tourism demand may further threaten the environmental quality and sustainability (Vedat, 2010).

However, Nigerians are said to be the most widely travelled nation on planet earth, and so, it is not surprising to note that the rate at which the Nigerian tourism industry is patronized is worrisome. At least, Bankole (2002:83) posits that Nigeria's size and tourism potentials correlate with tourism ratio in a downward trend when compared with other countries of the world; thus, affecting her GDP negatively. Many researchers in Nigeria with interest in the tourism sector have proven that the sector has the potential of not only contributing to foreign exchange earnings but also has the potential to reduce the concentration of foreign exchange sources. The weather, vegetation and climate render 
Nigeria a tourism destination of variety and contrast. Some factors (exchange rate volatility, insecurity, corruption, and dissatisfaction with the services rendered in these tourism locations) have crippled the activities in tourist locations in Nigeria. Existing literature have revealed that there are about four major determinants of international tourist flows: (i) the Real Effective Exchange Rate (REER); (ii) the relative prices between destination and origin; (iii) the income, approximated by the GDP of the origin country and (iv) the transportation cost (Cheng Ka Ming 2012, Zhang Yujuan, Hailin Qu and Pimtong Tavitiyaman 2009)

Despite the differences among studies, this study will focus on one variable often overlooked in the literature, which is exchange rate fluctuation, and how it affects the Tourism Sector. The main argument of empirical researchers is that excessive fluctuation of the exchange rate has the tendency to affect tour operations causing tourists to shift from a country with high exchange fluctuation to a country with low exchange rate fluctuation. This in turn affects the number of tourist arrival and the total contribution of tourism sector to the gross domestic product (GDP) of that country. George, Dimitrios, Nicholas (2015). In view of this, this study investigates the impact of exchange rate volatility on the tourism sector in Nigeria by examining the responses of the percentage share of the tourism sector to GDP to the consistent exchange rate volatility.

Furthermore, John (1995) defined tourism as the short-term movement of people away from their place of residence and work place to another destination for non-work reasons. Also in contributing to the definition, Paul (2000) defined tourism as any form of recreation activity that triggers the movement of an individual away from home for least one night, the choice of location is determine by the recreational interest of various individual. Therefore, in this sense, it highlighted that tourism involves the movement of people from a generating region to a destination region for the purpose of adventure or relaxation. Howbeit in line with the above definition, Nigeria with all its potentials in green vegetation, good climate, land formations, manmade creativities and art crafts, natural futures, divergent and heterogeneous culture, required the tourism sector to develop, yet the tourism sector has not grown significantly.

\section{Literature Review and Hypotheses Development}

A host of researchers across the world has investigated the dynamic relationship between tourism sector development and economic growth in a country and across regions employing different methods. Keeping in view the positive impact of tourism on economic growth some researchers have highlighted the major challenges faced by the tourism sector, it in this light that Ndanusa, Yoshifumi and Aminul (2014) theoretically study the challenges to the growth in tourism industry in Nigeria. The researcher conceptualize the challenges and potentials of Nigeria tourism sector as discussed in extended literatures and relevant industry reports and they arrived at the conclusion that the Nigeria government should exert political commitment and the will to drive the tourism industry for the development of the economy. The author further advocated that investment in tourism sector if properly manage and aimed to reduce poverty could directly benefit lowincome earners in the economy; as such, group of people can gain employment in tourism enterprises. It can further provide goods and services for tourist consumption through the running of small and community based enterprises etc., at the local level, which can trigger foreign earning through tax holiday or reduction on taxes and returns on investment.

In like note, Agiomirgianakis, Serenis, Tsounis (2014) used the co-integration analysis and autoregressive model approach to empirically examine the effect of exchange rate volatility on tourist flows into Turkey. The results revealed that exchange rate volatility has a negative relationship with inflows into Turkey. It further showed that the relative price ratio has a negative impact on the tourist arrival given the keen international competition among alternative destination. Therefore, the authors went further to suggest that any country that desire to improve its tourism sector, should in principle avoid policies that are prone to exchange rate volatility due to political and social up heaves or financial instability.

Likewise, Kilic and Bayar (2014) used a generalized autoregressive conditional heteroscedasticity (1.1) model to identify the effect of real exchange rate volatility on tourism receipts and expenditure in turkey for the period 1994 to 2013 . The results revealed that there is a positive long-term relationship between the real effective exchange rate and tourism receipts and expenditure. Agiomirgiakis, Sereni, Tsounis (2010) examined the effect of exchange rate volatility on tourist arrival from the period 1990 to 2004 in iceland. Using the cointegration, error correction methodology to represent the exchange rate volatility measure and using the Autoregressive Distributed Lag (ARDL) model of cointegration. The findings suggest that there is a negative effect of volatility to tourist arrival for Iceland. 
Ibimilua (2009) used in-depth, fieldwork observation, participation, focus group and interview method to appraise tourism potentials in Ekiti state, Nigeria. The result from the study showed that both manmade and natural potentials for recreation and tourism in Ekiti state are multifarious, though the level of development in the tourism sector grew at a very slow pace. The author recommends that the various stakeholders in the tourism sector should generate and put into place new master plan and policy for sustainable tourism in the state. Suggesting that the study will be of great interest to researchers, policy makers, tour operators, government in order to assist them in creating new initiatives for the development of adequate recreational centers and tourism sites.

Henry (2014) examines the socio-economic contributions of the Nigerian tourism sector and the small island of Northern Cyprus using the theoretical ideology of functionalism, the social survey method of analysis was adopted. The author concluded that corruption is strongly responsible for infrastructural decay in Nigeria. Adding that the correspondents from Nigeria and Northern Cyprus in this study are both assets to tourism benefits such as employment creation. The citizens of both countries share a similar propensity to travel outside the shore of their own countries and that tourism to both counties can be immense.

Webber (2001) examined the effects of Exchange Rate Volatility (ERV) on the number of tourist arrivals in Turkey for eighteen years using quarterly data. According to Webber (2001), the number of Tourist arrival is determine by the nature of the tourist, as some tourists are risk-lovers while others are risk averse. For risk-averse tourists ERV will have a negative effect on the decision to travel which will lower the number of arrival into the country, but it is likely to have a positive impact on risk seeking tourists as it will creates opportunities for the maximization of profits and therefore, leads to higher arrivals. On the Overall, the number of risk-averse tourists will increase drastically as compared to that of the risk-lovers; moreover, since tourist arrivals are dominated by package tourism, tour operators will switch locations to avoid ERV. Evidence from the results of the empirical analyses showed that ERV has a long run influence on tourism demand. Furthermore, the literature identified income elasticity as a key factor that influences the number of tourist arrivals: if the income at the origin country increases, more people will leave their domestic location travel abroad for vacation and other recreational activities. Tourism will have an income elasticity with values greater than one, i.e., tourism is a luxury good.

Stanley Plog (1972) proposes a theory that associates the popularity of a destination to the inherent personalities of travelers. Plog suggests that travelers can be classified based on their different personalities: allocentric, psychocentric, mid-centric, near allocentric and near psychocentric.

1) Allocentric: An allocentric tourist is any individual that adventurious and is willing to travel to a new location, environment, culture and adventure to engage in a number of activities. This individual is self-confident and outgoing in behavior. An allocentric person finds pleasure in exploring new experience before others discover such location. Allocentrics enjoy meeting people from foreign or different cultures, this set of individuals derive maximum satisfaction from lodging in beautiful hotels, environment and good food, but not necessarily modern or chain-type hotels. An allocentric individual enjoys a tour package that contains a well organised transportation route and hotels, but not been committed to a structured itinerary. They would rather enjoy the liberty to explore their destination, make their own arrangements and choose a variety of tourism activities and attractions.

2) Psychocentric are more conservative in their choice of tourist location, these individuals are non-adventuresome. They prefer to travel to familiar destinations where they have a prior knowledge of the types of food and activity to expect. Psychocentric prefer to travel to a familiar location, stay in typical tourist accommodations, and eat at known family-type restaurants. When arranging a package tour, psychocentric would structure out an organize travel itinerary so that they know what to expect. This type of tourist considers Safety and security factor of their destination as well as the environmental factor.

3) Mid-centric: a good number of tourist fall between the allocentric and the psychocentric types of tourists, this type of individuals are known as mid-centrics tourist. Mid-centric tourists are not adventurous in nature, but they seek new experience.

Most tourist that visit Nigeria are allocentric, they seek new destinations and are prepared to take risk in searching for new culture and places. They are adventurous and great explorers willing to visit tourist areas in the northern part of the country even with the insecurity challenge presently prevailing in such part of the nation. 
No of tourist

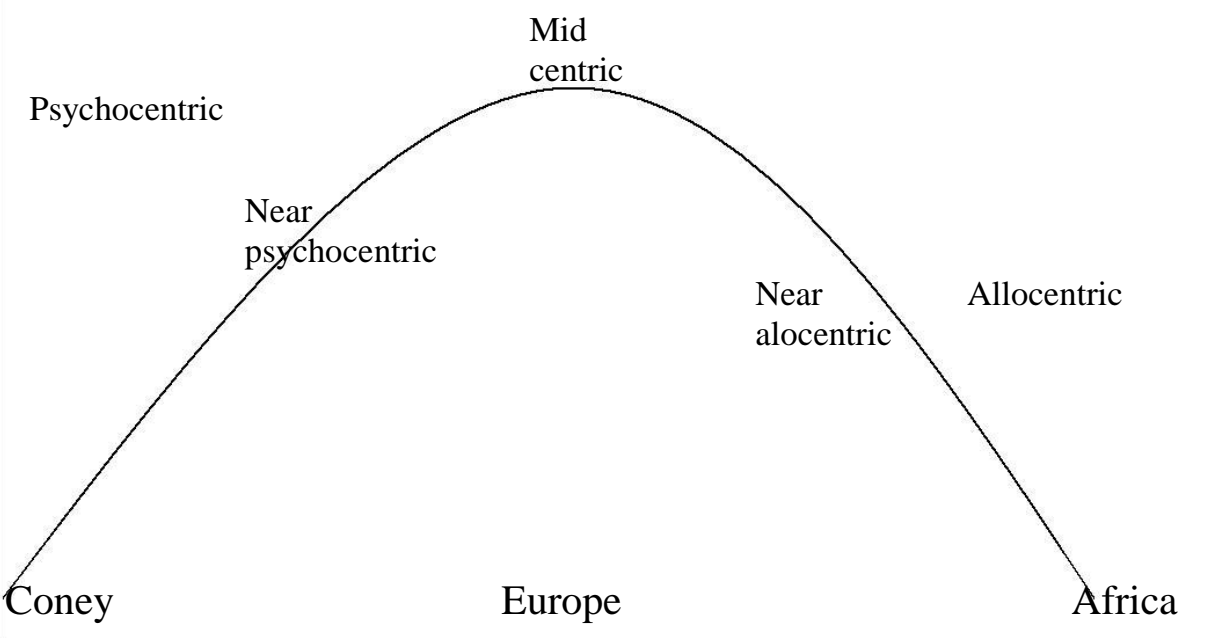

Figure 1: Diagram on Plog's Classification of a Tourist (Source: Mehmet \& Yorucu, (2010) )

\section{Methodology}

Based on the available data and the previous research by Serenis and Tsounis (2014) to examine the effects of ERVon tourism sector contribution to GDP, we specify the model in Nigeria as follows:

$\operatorname{lnTSGDP}=\mathrm{BO}+\mathrm{B} 1 \ln R E E R+\mathrm{B} 2 \ln \mathrm{TSEM}+\mathrm{B} 3 \ln \mathrm{TX}+\mathrm{U}$

Where:

TSGDP $=$ the contribution of tourism sector to the GDP,

TSEM = Represents contribution of the Tourism sector to employment,

$\mathrm{TX}=$ The international number of tourist arrival. Finally,

REER $=$ Represents exchange rate volatility which is measured as a measure of high and low fluctuation of the average values of volatility by utilizing a variable that captures high and low peak values of the Real Effective Exchange Rate (REER).

All the variables of the study are expressed in their natural logarithms to avoid the problem of heteroscedasticity; B's are the parameters of the model to be estimated and relying on the literature it is expected that estimates of B1 >0 and B2 > 0 .

\subsection{Sources of data}

The study uses annual data of the variables TSGDP and TSEM, which were obtained from World Tourism Council data base while data on TX and REER were obtained online from World Development Indicators of the World Bank from the period of 1995-2015. 


\section{Data Analysis, Results and Discussions}

The Granger Causality test is used to investigate the existence of causal relationships among the variables involved. However, before this is done, the data used for the study is subject to unit root testing through the use of the Augmented Dickey Fuller and Phillips-Perron-unit root test.

\subsection{Unit Root Test}

Table 1: Augmented Dickey Fuller (ADF) Unit Root Test

\begin{tabular}{|l|l|l|l|}
\hline Variable & $\begin{array}{l}\text { ADF T-Statistic } \\
\text { at First Difference }\end{array}$ & ADF Critical values at 1\% & Decision \\
\hline LTSGDP & $-4.7007 * * *$ & -4.38 & $\mathrm{I}(1)$ \\
\hline LTSEM & $-5.2055^{* * *}$ & -4.38 & $\mathrm{I}(1)$ \\
\hline LREER & $-12.7024 * * *$ & -4.38 & $\mathrm{I}(1)$ \\
\hline LTX & $-4.4446 *$ & -4.38 & $\mathrm{I}(1)$ \\
\hline
\end{tabular}

$*, * *, * * *$ Represents stationarity at $10 \%, 5 \%$ and $1 \%$ level of significance respectively

Table 2: Philip-Perron Unit Root Test

\begin{tabular}{|l|l|l|l|}
\hline Variables & $\begin{array}{l}\text { ADF T-Statistic } \\
\text { at First Difference }\end{array}$ & $\begin{array}{l}\text { ADF Critical values at } \\
\mathbf{1 \%}\end{array}$ & Decision \\
\hline LTSGDP & -4.651 & -4.534844 & $\mathrm{I}(1)$ \\
\hline LTSEM & -5.7429 & -4.534844 & $\mathrm{I}(1)$ \\
\hline LREER & -4.896 & -4.534844 & $\mathrm{I}(1)$ \\
\hline LTX & -4.6082 & -4.534844 & $\mathrm{I}(1)$ \\
\hline
\end{tabular}

The result of the unit root stationarity test shown in tables 1 and 2 were conducted using Augmented Dickey Fuller (ADF) and Phillip Perron (PP). The result of the ADF and PP test revealed that all the variables were not stationary at level, Therefore the entire series were subjected to further test at first differencing. It is evidence that all the variables achieved a stationary trend process after the first differencing for both the ADF and PP tests. Hence, the null hypothesis of unit root could no longer be accepted for the variables at this level. This means that the series is regarded to be integrated to order (1) process.

\subsection{Granger Causality Wald Test}

To determine the nature of the causal relationship among the included variables in the model, the study is further subjected to a granger causality test.

Table 3: Granger Causality Wald Test

\begin{tabular}{|l|l|l|}
\hline Null hypothesis & X2-square & Probability \\
\hline LTX does not granger cause LTSGDP & 8.8564 & 0.012 \\
\hline LTSGDP does not granger cause LTX & 0.9058 & 0.636 \\
\hline LREER does not granger cause LTSGDP & 8.7236 & 0.013 \\
\hline LTSGDP does not granger cause LREER & 1.8239 & 0.402 \\
\hline LTSEM does not granger cause LTSGDP & 13.642 & 0.001 \\
\hline TSGDP does not granger cause LTSEM & 0.4665 & 0.792 \\
\hline
\end{tabular}

The granger Causality test result showed that there is a unidirectional causality between (TSGDP) contribution of tourism sector to GDP and the independent variables (TSEM, REER, TX). The contribution of the Tourism sector to employment (TSEM), Real effective exchange rate (REER), and the international number of tourist arrival (TX) granger cause the economic growth (TSGDP) but economic growth does not granger cause any of these independent variables, the results is evident at 5 percent level of significant. 


\subsection{Co-integration test Results}

Co-integration Result analysis is a technique employed to test for the existence of a statistically significant relationship among two or more-time series variables this is done by testing for the existence of a cointegrated combination of the two series. If such a combination has a low order of integration, this can signify an equilibrium relationship between the original series, which are said to be co-integrated. Agiomirgiakis, Sereni, Tsounis (2010)

The result of the unit root tests showed that all variables are stationary at first difference, we proceeded to test for the existence of any co integration among the variables in the model. The Engle and Granger (1987) two-step procedure for co integration analysis was used to determine whether there is a long run relationship between the output contribution of tourism sector to economic growth, and real effective exchange rate in the Nigerian economic, because there are only $\mathrm{I}(1)$ variables in the model.

Table 4: Engle Granger Cointegration Test

\begin{tabular}{|l|l|l|l|}
\hline Variables & $\begin{array}{l}\text { ADF T-Statistic at } \\
\text { LEVEL }\end{array}$ & $\begin{array}{l}\text { ADF Critical values at } \\
\mathbf{1 \%}\end{array}$ & Decision \\
\hline RESIDS & 2.7178 & 2.66 & $\mathrm{I}(0)$ \\
\hline
\end{tabular}

The results from the Engle granger cointegration test where we test if the residual (ut) are stationary by using the Augmented Dickey Fuller Test, the result showed that at level the residuals are stationary at I percent critical level. This result implies that in the long run all variables are cointegrated, there is a long run relationship between economic growth, real effective exchange rate, number of international tourist arrival and tourism contribution to employment.

\subsection{Vector Error Correction Model}

Since the results from our cointegration test showed that all variables are cointegrated we ran the Vector Error Correction Model. The Vector Error Correction modelling (VECM) allows for the determination of the short run adjustment process towards the long run equilibrium state in the system. The VECM indicates the speed of adjustment from short run equilibrium state to that of the long run (Yusuf and Akinde 2015). A greater co-efficient on the parameters indicates that the speed of adjustment of the model from the short run to the long run is higher.

Table 5: Vector Error Correction Model

\begin{tabular}{|l|l|l|l|l|}
\hline Variables & Coefficient & STD. Error & Z-Value & P-Value \\
\hline EC(-1) & -0.5387506 & 0.1302037 & -4.14 & 0.000 \\
\hline DLTSGDP(L1) & 0.6604684 & 0.2219633 & 2.98 & 0.003 \\
\hline DLTSGDP(L2) & 0.3737216 & 0.2036073 & 1.84 & 0.066 \\
\hline DLREER(L1) & -1.026227 & 0.5730291 & -1.79 & 0.043 \\
\hline DLREER(L2) & 0.7186252 & 0.5233917 & 1.37 & 0.170 \\
\hline DLTSEM(L1) & -0.4258661 & 0.1235762 & -3.45 & 0.0001 \\
\hline DLTSEM(L2) & -0.9198326 & 0.1437551 & -6.40 & 0.000 \\
\hline DLTX(L1) & 0.0002161 & 0.0000459 & 4.17 & 0.000 \\
\hline DLTX(L2) & 0.0000612 & 0.0000435 & 1.41 & 0.159 \\
\hline Cons & 41.36094 & 30.50432 & 1.36 & 0.175 \\
\hline
\end{tabular}

The results from the VECM model revealed that the error correction term (EC) is statistically significant at $5 \%$. This implies that there exists a dynamic adjustment from short run to long run, the EC coefficient is 0.54 approximately indicating that $54 \%$ of the errors in the short run are corrected in the long run. Generally, the EC term in the model shows that the speed of adjustment from short run equilibrium to the long run state. Since the coefficient of the EC term is statistically it also shows us that there is a long run causality running from LREER, LTSEM, and LTX to LTSGDP.

As regards the behaviour of the independent variables with respect to the dependent variable, a long run causality exists between the first lag of LREER and LTSGDP. The result further shows that there is a negative relationship between the 
first lag of LREER and LTSGDP confirming to apriori expectation, fluctuation in log of real exchange rate has a negative impact on the log of the share of tourism sector output to GDP.

Secondly, the relationship between the log of the number of international tourist arrival (LTX) and LTSGDP also conforms to apriori expectation given a positive coefficient. The higher the number of tourist arriving into the country the higher the contribution of the tourist sector to GDP.

\section{Conclusion}

This study has examined the dynamic relationship between real effective exchange rate fluctuation and the contribution of tourism sector output in Nigeria measured by the share of tourism sector in GDP for the period 1995 to 2015 . Our conclusions were drawn from the results gotten from the cointegration, vector error correction model (VECM) and granger causality test. The result of the granger causality test revealed that there is a unidirectional causality between the tourism sector output and real effective exchange rate, number of international tourist arrival and tourism sector contribution to employment. While the result from the Engle Granger cointegration test showed that all the variables in the model are Cointegrated in the long run, implying that a long run relationship exists between the contribution of tourism sector to GDP and real effective exchange rate, tourism sector contribution to employment and number of international tourist arrival.

Finally, the VECM revealed that exchange rate fluctuation has indeed a significantly negative effect on tourism sector output in Nigeria. Increased fluctuation reduces the contribution of the tourism sector to GDP, implying that potential tourist as well as tour operators are constantly been affected by the choice of travel destinations or location by the extreme value of exchange rate than by other factors.

\section{Recommendation}

Nigeria has potential tourism destination that can attract every class of tourist as postulated in Plog's Classification of tourist (Plog 1972). The natural climate and environmental features in the country can stimulate the number of international tourist arrival to Nigeria. The United Nations World Tourism Organizations (UNWTO) has projected the increase in tourist arrival to Africa to have an average long term growth rate of $4.4 \%$ a year, which has been predicted to reach 1.8 billion by 2030 (UNWTO 2015). The fluctuation in exchange rate is seen as one of the greatest problem facing the Nigeria tourism sector and affecting its competitiveness with other tourism destination such as Kenya, south Africa and others, we therefore recommend the following.

The recent diversification innovation by the government of Nigeria from the oil sector to non-oil producing sectors such as tourism, the government should discard the idea of exercising exchange rate policies for other policy objectives, as these policies could cause an increase in exchange rate fluctuation that could, substantially reduce the number of tourist arrival and tourism sector output.

Competition among destination countries in attracting tourists from all over the world is very keen; and is determine by political factors and social stability, safety and security at the destination country. Economic Instability are perceived by tourists through the fluctuation in Exchange Rate of that country, which is attributed to the economic policies formulated by policymakers in the tourist destination country. The government should create and implement more policies that can trigger political and social stability and national security and this can further stabilize the exchange rate and attract more tourists into the country.

3. Increasing the Attractiveness of tourist Destinations through Cultural Resources is another factor that can increase the inflow of both domestic and international tourist. Culture is a major motivator for tourism, social cohesion, support for the cultural sector, increase innovation and creativity will increase the number of tourist arrival and revenue for the tourism sector. State government should innovate more annual carnivals to showcase their various culture, as this will trigger the inflow of tourist into Nigeria and also increase tourism sector output. 


\section{References}

- Agiomirgianakis, G. and George, S. (2014). Determinants of Tourism Demand in Greece: A Panel Data Approach. Ekonometria Econometrics Journal 1(43), 16-26, CrossRef

- Ayeni, D. \& Ebohon, O. (2014). Exploring Sustainable Tourism in Nigeria for Developmental Growth. European Scientific Journal, 8(20), 126-140.

- Bankole, A. (2002). The Nigerian Tourism Sector: Economic Contribution, Constraints, and Opportunities. Journal of Hospitality Financial Management, 10(1), 71-89, CrossRef

- Cheng, K. M (2012). Tourism demand in Hong Kong: income, prices, and visa restrictions. Current Issues in Tourism, 15(1), 167-181, CrossRef

- Cüneyt, K. \& Yilmaz, B. (2014). Effects of Real Exchange Rate Volatility on Tourism Receipts and Expenditures in Turkey. Journal of Advances in Management \& Applied Economics, 4(1), 89-101.

- George, A. Dimitrios, S. \& Nicholas, T. (2015). Exchange Rate Volatility and Tourist Flows into Turkey. Journal of Economic Integration, 29(4), 700-725.

- Henry, C. O. (2014). The Socio-Economic Contribution of Tourism to Nigeria and North Cyprus: A Comparative Approach. Project Work of Cyprus International University Institute of Graduate Studies and Research, Business Administration Department.

- Ibimilua, A. F. (2009). Tourism Participation: Attractions, Influences and Key Trends in Ekiti State, Nigeria. An International Multi-Disciplinary Journal, 3(3), (244-258), CrossRef

- Mehmet, O. \& Yorucu, V. (2010) Efficiency Gains in Tourism in Cyprus: Myth or Reality. Turkish Studies, 11 (3), 477-96, CrossRef

- Ndanusa. M. N, Yoshifumi, H. \& Aminul, I. (2014). Challenges to Growth in Tourism Industry of a Developing Country: The Case of Nigeria. Asian Social Science Journal, 10(19), 282-289, CrossRef

- Webber, A. G. (2001). Exchange Rate Volatility and Co-integration in Tourism Demand. Journal of travel Research 39(1), 398-405, CrossRef

- Yusuf, M. \& Akinde, M. (2015). Tourism Development and Economic Growth Nexus: Nigeria's Experience. European Journal of Hospitality and Tourism Research, 3(4), 1-10.

- Zhang, Y. Hailin, Q. \& Pimtong, T. (2009). The Determinants of the Travel Demand on International Tourist Arrivals to Thailand. Asia Pacific Journal of Tourism Research, 14(2), 77-92, CrossRef 